Buletin Ilmiah Mat. Stat. dan Terapannya (Bimaster)

Volume 08, No. 3 (2019), hal 613-618.

\title{
OPTIMALISASI WAKTU PRODUKSI MINYAK KELAPA DENGAN METODE PERT \\ (Studi Kasus pada Data Produksi Minyak Kelapa CV. Usaha Bersama Kabupaten Sambas)
}

\begin{abstract}
Waliyanti, Helmi, Yundari
INTISARI

Proses produksi minyak kelapa memerlukan penjadwalan agar bisa teratur dan selesai dalam waktu yang optimal. Suatu metode yang menganalisis waktu optimal untuk menyelesaikan produktivitas minyak kelapa adalah metode PERT (Program Evaluation and Review Technique). Metode PERT adalah metode analisis yang digunakan dalam situasi memperkirakan waktu yang belum pasti. Data yang digunakan dalam penelitian ini merupakan data primer yang diperoleh dari CV. Usaha Bersama Kabupaten Sambas berupa data durasi waktu setiap aktivitas produksi minyak kelapa. Langkah awal mengidentifikasi setiap durasi waktu aktivitas produksi dan mencari estimasi waktu yang diharapkan $\left(T_{e}\right)$. Pengidentifikasian jalur kritis dengan menggunakan Analisis Network dilakukan untuk melihat hubungan ketergantungan antara bagian-bagian aktivitas. Selanjutnya perhitungan varians $\left(\sigma^{2}\right)$ disetiap jalur kritis dan deviasi standar $(\sigma)$ keseluruhan aktivitas digunakan untuk mengetahui besar probabilitas. Hasil penelitian menunjukkan bahwa pengoptimalan waktu yang diharapkan pada produksi minyak kelapa selesai dalam waktu 309 jam.
\end{abstract}

Kata Kunci: metode PERT, analisis network, optimalisasi

\section{PENDAHULUAN}

Minyak kelapa murni adalah minyak kelapa yang dibuat dari bahan baku kelapa segar, diproses dengan pemanasan terkontrol tanpa bahan kimia. Produktivitas minyak kelapa memerlukan penjadwalan agar bisa teratur dan selesai dalam waktu yang optimal. Ada dua metode yang digunakan untuk pengoptimalan waktu produksi yaitu metode PERT dan metode CPM. PERT atau Program Evaluation and Review Technique adalah sebuah model Management Science untuk perencanaan dan pengendalian sebuah proyek[1]. PERT dikembangkan oleh perusahaan konsultan Booz-Allen dan Hamilton pada tahun 1958-1959[1]. Metode CPM atau Critical Path Method diperkenalkan oleh JE Kelly dari Remington Rand dan MR Walker pada tahun 1957[2]. PERT dipergunakan pada proyek yang taksiran waktu aktivitas-aktivitasnya tidak bisa dipastikan. Sementara $C P M$ digunakan apabila taksiran waktu pengerjaan setiap aktivitas sudah pasti[2]. Metode PERT memberikan tiga estimasi durasi waktu bermaksud untuk menampung adanya unsur-unsur yang belum pasti, sehingga dianalisis kemungkinan-kemungkinan sejauh mana proyek menyimpang atau memenuhi sasaran dalam proses produksi. Oleh karena itu, PERT banyak digunakan dalam bidang penelitian dan pengembangan, yang sering sekali memiliki durasi waktu dari masing-masing kegiatan yang belum pasti[1]. Pada penelitian ini digunakan durasi waktu pada produksi minyak kelapa.

Pengoptimalan produksi minyak kelapa memerlukan beberapa tahapan, pertama identifikasi data durasi waktu setiap aktivitas. Kemudian menganalisis estimasi waktu setiap aktivitas dengan menggunakan Metode PERT. Setelah itu menganalisis probabilitas pada Metode PERT dengan menggunakan distribusi normal standar. Production, Planning and Control (perencanaan dan pengendalian produksi) tidak terlepas dari istilah manufacturing (manufaktur) yang merupakan suatu proses produksi dalam menghasilkan produk-produk yang bersifat fisik/ada wujudnya (tangible product)[3]. 


\section{METODE PERT}

Metode PERT menggunakan pendekatan waktu dengan memberikan tiga angka estimasi waktu untuk setiap kegiatan, yaitu waktu yang paling mungkin (most likely estimate) $(m)$ merupakan estimasi waktu yang sering terjadi dibanding dengan yang lain bila aktivitas dilakukan berulang-ulang dengan kondisi yang hampir sama.Waktu optimistik (optimistic estimate) (a) merupakan estimasi waktu tersingkat untuk menyelesaikan aktivitas bila segala sesuatunya berjalan dengan mulus. Waktu demikian diungguli hanya sekali dalam seratus kali bila aktivitas tersebut dilakukan berulang-ulang dengan kondisi yang hampir sama. Waktu pesimistik (pessimistic estimate) (b) merupakan estimasi waktu yang paling lama untuk menyelesaikan aktivitas, yaitu memiliki kendala dalam aktivitas. Waktu demikian dilampaui hanya sekali dalam seratus kali bila aktivitas dilakukan berulang-ulang dengan kondisi yang hampir sama. Adapun persamaan dari metode PERT adalah seperti pada Persamaan (1)[4], yaitu

$$
T_{e}=\frac{a+4 m+b}{6},
$$

dengan

$T_{e} \quad$ = waktu yang diharapkan

$a \quad=$ waktu optimistik

$m \quad$ = waktu yang paling mungkin

$b \quad=$ waktu pesimistik.

Waktu yang diharapkan dari setiap aktivtas produksi minyak kelapa yang didapat dari perhitungan digunakan sebagai durasi waktu setiap aktivitas.

\section{ANALISIS JARINGAN KERJA (NETWORK)}

Jaringan kerja (network) adalah hubungan ketergantungan antara bagian-bagian aktivitas yang digambarkan dalam diagram network. Untuk menggambarkan jaringan kerja (network) diperlukan beberapa simbol seperti pada Tabel 1[5].

Tabel 1 Simbol Analisis Jaringan Kerja (Network)

\begin{tabular}{|c|l|}
\hline Simbol & \multicolumn{1}{c|}{ Keterangan } \\
\hline$\longrightarrow$ & $\begin{array}{l}\text { garis panah mengambarkan suatu kegiatan yang membutuhkan waktu dan biaya dalam } \\
\text { pengerjaannya. }\end{array}$ \\
\hline$\longrightarrow$ & $\begin{array}{l}\text { lingkaran mengambarkan suatu kegiatan yang menandakan awal dan akhirnya suatu kegiatan, } \\
\text { dalam lingkaran terdapat dua lingkaran yang mengawali dan mengakhiri kegiatan tersebut. }\end{array}$ \\
\hline$\longrightarrow$ & $\begin{array}{l}\text { garis panah putus-putus menggambarkan kegiatan semu atau dummy activity. Kegiatan dummy } \\
\text { tidak memakan waktu dan sumber daya, jadi waktu dan biaya kegiatan sama dengan nol. }\end{array}$ \\
\hline & garis panah tebal menggambarkan kegiatan pada lintasan kritis. \\
\hline
\end{tabular}

\section{JALUR KRITIS}

Jalur kritis merupakan jalur terpanjang/terlama dalam penyelesaian proyek. Pencarian jalur kritis dilakukan dengan dua pendekatan yaitu pendekatan kejadian dan pendekatan kegiatan[5]. Jalur kritis dapat dicari dengan menggunakan analisis network seperti pada Gambar 1.

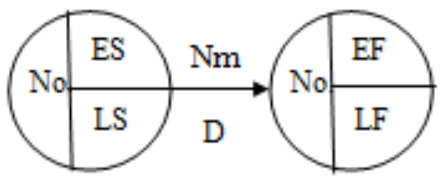

\section{Gambar 1 Analisis Network dari Suatu Aktivitas}

dengan,

No $=$ nomor simpul aktivitas.

$\mathrm{Nm} \quad=$ nama aktivitas.
D = durasi waktu aktivitas.

ES = waktu mulai paling awal 
LS = waktu mulai paling akhir

EF =watu selesai paling awal

LF = waktu selesai paling akhir.

ES merupakan durasi waktu awal pengerjaan aktivitas. EF merupakan durasi waktu selesai awal pengerjaan aktivitas yang diperoleh dari ES + D. LF merupakan durasi waktu selesai akhir pengerjaan aktivitas. EF merupakan durasi waktu mulai akhir pengerjaan aktivitas yang diperoleh dari LF - D. Jika nilai LF dikurang dengan nilai EF sama dengan 0, maka aktivitas merupakan jalur kritis.

\section{DISTRIBUSI NORMAL STANDAR}

Distribusi normal standar merupakan hasil dari transformasi distribusi normal dengan parameter $\mu$ dan $\sigma$. Adapun fungsi kepadatan peluang distibusi normal standar dituliskan sebagai berikut[6],

$$
f(z ; 0,1)=\frac{1}{\sqrt{2 \pi}} e^{-\frac{1}{2} z^{2}},
$$

dengan $z$ merupakan variabel acak pada distribusi normal standar.

\section{STUDI KASUS}

Data yang digunakan pada penelitian ini berupa data primer yaitu data durasi waktu setiap aktivitas produksi minyak kelapa. Data ini diperoleh dari CV. Usaha Bersama Kabupaten Sambas. Berikut aktivitas-aktivitas produksi minyak kelapa disajikan pada Tabel 2.

Tabel 2 Simbol dan Nama Aktivitas

\begin{tabular}{|c|l|}
\hline $\begin{array}{c}\text { Simbol } \\
\text { Aktivitas }\end{array}$ & \multicolumn{1}{|c|}{ Nama Aktivitas } \\
\hline$x_{1}$ & Pembelian Bahan Baku \\
$x_{2}$ & Penimbangan Bahan Baku \\
$x_{3}$ & Pengisian Wadah Penyalaian \\
$x_{4}$ & Penyalaian \\
$x_{5}$ & Penyalinan ke Lift Satu \\
$x_{6}$ & Pemotongan Daging Kelapa \\
$x_{7}$ & Penyalinan dari Hasil Pemotongan \\
$x_{8}$ & Penggilingan Tahap Satu \\
$x_{9}$ & Penyalinan Minyak Hasil Gilingan Satu \\
$x_{10}$ & Penyalinan Ampas Dari Gilingan Satu \\
$x_{11}$ & Penyalinan ke Lift Dua \\
\hline
\end{tabular}

\begin{tabular}{|c|l|}
\hline $\begin{array}{c}\text { Simbol } \\
\text { Aktivitas }\end{array}$ & \multicolumn{1}{|c|}{ Nama Aktivitas } \\
\hline$x_{12}$ & Penyalinan dari Lift Dua \\
$x_{13}$ & Penggilingan Tahap Dua \\
$x_{14}$ & Penyalinan dari Hasil Gilingan Tahap Dua \\
$x_{15}$ & Penyalinan Ampas dari Gilingan Tahap Dua \\
$x_{16}$ & Penyalinan ke Penampung Makanan Ternak \\
$x_{17}$ & Penyalinan Minyak Gabungan \\
$x_{18}$ & Penyaringan Minyak \\
$x_{19}$ & Penyalinan Minyak Bersih \\
$x_{20}$ & Penyalinan Minyak Siap Kirim \\
$x_{21}$ & Pemasaran \\
\hline
\end{tabular}

Tabel 2 merupakan simbol dan nama aktivitas-aktivitas yang ada dalam produksi minyak kelapa. Selanjutnya menganalisis durasi waktu setiap aktivitas produksi minyak kelapa disajikan pada Tabel 3.

Tabel 3 Durasi Waktu Setiap Aktivitas dan Estimasi Waktu yang Diharapkan

\begin{tabular}{|c|c|c|c|c|}
\hline $\begin{array}{c}\text { Simbol } \\
\text { Aktivitas }\end{array}$ & $a($ Jam $)$ & m(Jam) & $b$ (Jam) & $\begin{array}{c}T_{e} \\
\text { (Jam) }\end{array}$ \\
\hline$x_{1}$ & 10 & 20 & 30 & 20 \\
$x_{2}$ & 10 & 20 & 30 & 20 \\
$x_{3}$ & 10 & 20 & 30 & 20 \\
$x_{4}$ & 60 & 80 & 100 & 80 \\
$x_{5}$ & 5 & 10 & 15 & 10 \\
$x_{6}$ & 10 & 10 & 15 & 10,83 \\
$x_{7}$ & 10 & 10 & 15 & 10,83 \\
$x_{8}$ & 10 & 10 & 15 & 10,83 \\
$x_{9}$ & 10 & 10 & 15 & 10,83 \\
$x_{10}$ & 10 & 10 & 15 & 10,83 \\
$x_{11}$ & 10 & 10 & 15 & 10,83 \\
\hline \multicolumn{5}{|r}{}
\end{tabular}

\begin{tabular}{|c|c|c|c|c|}
\hline $\begin{array}{c}\text { Simbol } \\
\text { Aktivitas }\end{array}$ & $a(\mathrm{Jam})$ & $m$ (Jam) & b(Jam) & $\begin{array}{c}T_{e} \\
\text { (Jam) }\end{array}$ \\
\hline$x_{12}$ & 10 & 10 & 15 & 10,83 \\
$x_{13}$ & 10 & 10 & 15 & 10,83 \\
$x_{14}$ & 10 & 10 & 15 & 10,83 \\
$x_{15}$ & 10 & 10 & 15 & 10,83 \\
$x_{16}$ & 10 & 10 & 15 & 10,83 \\
$x_{17}$ & 10 & 10 & 15 & 10,83 \\
$x_{18}$ & 5 & 7 & 10 & 7,17 \\
$x_{19}$ & 5 & 7 & 10 & 7,17 \\
$x_{20}$ & 15 & 20 & 70 & 27,5 \\
$x_{21}$ & 10 & 10 & 70 & 20 \\
\hline
\end{tabular}


Tabel 3 setiap aktivitas memiliki tiga estimasi durasi waktu pengerjaannya yaitu $a$, $m$, dan $b$. Aktivitas $x_{l}$ memiliki waktu penyelesaian optimistik selama 10 jam, waktu penyelesaian paling mungkin selama 20 jam dan waktu penyelesaian pesimistik selama 30 jam. Selanjutnya dengan menggunakan Persamaan (1) diperoleh nilai $T_{e}$, untuk aktivitas $x_{l}$ dengan durari waktu Selma 20 jam. Begitu juga untuk pengerjaan aktivitas lainnya. Kemudian menganalisis jalur kritis disetiap aktivitas produksi minyak kelapa seperti pada Tabel 5.

Tabel 4 Mencari Jalur Kritis dan Bukan Jalur Keritis pada Aktivitas-Aktivitas

\begin{tabular}{|c|c|c|c|c|c|c|c|}
\hline $\begin{array}{l}\text { Simbol } \\
\text { Aktivitas }\end{array}$ & $\begin{array}{c}\text { Waktu } \\
\text { Aktivitas } \\
\mathrm{T}_{\mathrm{e}} \text { (Jam) }\end{array}$ & ES(Jam) & EF(Jam) & LS(Jam) & LF(Jam) & $\begin{array}{c}\text { Slack } \\
\text { (Jam) }\end{array}$ & Ket. \\
\hline$x_{1}$ & 20 & 0 & 20 & 0 & 20 & 0 & $*$ \\
$x_{2}$ & 20 & 20 & 40 & 20 & 40 & 0 & $*$ \\
$x_{3}$ & 20 & 40 & 60 & 40 & 60 & 0 & $*$ \\
$x_{4}$ & 80 & 60 & 140 & 60 & 140 & 0 & $*$ \\
$x_{5}$ & 10 & 140 & 150 & 140 & 150 & 0 & $*$ \\
$x_{6}$ & 10,83 & 150 & 160,83 & 150 & 160,83 & 0 & $*$ \\
$x_{7}$ & 10,83 & 160,83 & 171,67 & 160,83 & 171,67 & 0 & $*$ \\
$x_{8}$ & 10,83 & 171,67 & 182,5 & 171,67 & 182,5 & 0 & $*$ \\
$x_{9}$ & 10,83 & 182,5 & 193,33 & 225,83 & 236,67 & 43,33 & - \\
$x_{10}$ & 10,83 & 182,5 & 193,33 & 182,5 & 193,33 & 0 & $*$ \\
$x_{11}$ & 10,83 & 193,33 & 204,17 & 193,33 & 204,17 & 0 & $*$ \\
$x_{12}$ & 10,83 & 204,17 & 215 & 204,17 & 215 & 0 & $*$ \\
$x_{13}$ & 10,83 & 215 & 225,83 & 215 & 225,83 & 0 & $*$ \\
$x_{14}$ & 10,83 & 225,83 & 236,67 & 225,83 & 236,67 & 0 & $*$ \\
$x_{15}$ & 10,83 & 225,83 & 236,67 & 236,67 & 278,5 & 41,83 & - \\
$x_{16}$ & 10,83 & 236,67 & 247,5 & 247,5 & 289,33 & 41,83 & - \\
$x_{17}$ & 10,83 & 236,67 & 247,5 & 284,17 & 247,5 & 0 & $*$ \\
$x_{18}$ & 7,17 & 247,5 & 254,67 & 247,5 & 254,67 & 0 & $*$ \\
$x_{19}$ & 7,17 & 254,67 & 261,83 & 254,67 & 261,83 & 0 & $*$ \\
$x_{20}$ & 27,5 & 261,83 & 289,33 & 261,83 & 289,33 & 0 & $*$ \\
$x_{21}$ & 20 & 289,33 & 309,33 & 289,33 & 309,33 & 0 & $*$ \\
\hline
\end{tabular}

Pada Tabel 4 ada tiga aktivitas yang bukan merupakan jalur kritis yaitu aktivitas $x_{9}, x_{15}$ dan $x_{16}$. Ketiga aktivitas yang bukan merupakan aktivitas jalur kritis bisa diabaian dalam proses produksi minyak kelapa. Langkah selanjutnya menganalisis probabilitas dari produksi minyak kelapa yang terlaksana atau tidak, menggunakan data durasi waktu $T_{e}$ dan $\sigma$ dari proses produksi minyak kelapa. Pertama akan dicari varian setiap aktivitas dengan menggunakan Persamaan (3)[7],

$$
\sigma_{x_{i}}^{2}=\left(\frac{b-a}{6}\right)^{2} .
$$

Hasil dari perhitungan variansi untuk setiap aktivitas dapat dilihat pada Tabel 5. 
Tabel 5 Mencari Varian untuk Setiap Aktivitas

\begin{tabular}{|c|c|c|c|c|c|c|c|c|c|}
\hline $\begin{array}{c}\text { imbol } \\
\text { Aktivitas }\end{array}$ & $a(j a m)$ & $m(\mathrm{Jam})$ & $b(J a m)$ & $\sigma^{2}(\mathrm{Jam})$ & $\begin{array}{c}\text { imbol } \\
\text { Aktivitas }\end{array}$ & $a(j a m)$ & $m(\mathrm{Jam})$ & $b(\mathrm{Jam})$ & $\sigma^{2}(\mathrm{Jam})$ \\
\hline$x_{1}$ & 10 & 20 & 30 & 11,11 & $x_{12}$ & 10 & 10 & 15 & 0,69 \\
\hline$x_{2}$ & 10 & 20 & 30 & 11,11 & $x_{13}$ & 10 & 10 & 15 & 0,69 \\
\hline$x_{3}$ & 10 & 20 & 30 & 11,11 & $x_{14}$ & 10 & 10 & 15 & 0,69 \\
\hline$x_{4}$ & 60 & 80 & 100 & 44,44 & $x_{15}$ & 10 & 10 & 15 & 0,69 \\
\hline$x_{5}$ & 5 & 10 & 15 & 0,69 & $x_{16}$ & 10 & 10 & 15 & 0,69 \\
\hline$x_{6}$ & 10 & 10 & 15 & 0,69 & $x_{17}$ & 10 & 10 & 15 & 0,69 \\
\hline$x_{7}$ & 10 & 10 & 15 & 0,69 & $x_{18}$ & 5 & 7 & 10 & 0,69 \\
\hline$x_{8}$ & 10 & 10 & 15 & 0,69 & $x_{19}$ & 5 & 7 & 10 & 0,69 \\
\hline$x_{9}$ & 10 & 10 & 15 & 0,69 & $x_{20}$ & 15 & 20 & 70 & 84,03 \\
\hline$x_{10}$ & 10 & 10 & 15 & 0,69 & $x_{21}$ & 10 & 10 & 70 & 100 \\
\hline$x_{11}$ & 10 & 10 & 15 & 0,69 & & & & & \\
\hline
\end{tabular}

Pada Tabel 5 nilai varian pada aktivitas $x_{1}$ yang diperoleh dari Persamaan (3) adalah selama 11,11 jam. Begitu juga untuk pengerjaan aktivitas lainnya. Kemudian dihitung deviasi standar keseluruhan aktivitas dengan Persamaan (4)[7].

$$
\sigma=\sqrt{\sum_{i=1}^{N} \sigma_{i}^{2}(\text { jalur kritis })}
$$

Selanjutnya diperoleh hasil sebagai berikut.

$$
\begin{aligned}
\sigma & =\sqrt{\sum_{i=1}^{18} \sigma_{i}^{2}(\text { jalur kritis })} \\
\sigma & =\sqrt{11,11+11,11+11,11+44,44+2,78+0,96+0,96+0,96+0,96+0,96+0,96+0,96+\ldots+100} \\
& =\sqrt{271,54} \\
& =16,48 \mathrm{jam} .
\end{aligned}
$$

Deviasi standar dari keseluruhan aktivitas pada jalur kritis selama 16,48 jam. Kemudian dicari distribusi normal standar dengan Persamaan (5)[7],

$$
z=\frac{D-T_{e}}{\sigma}
$$

dengan $D$ sebagai durasi waktu keseluruhan aktivitas dan diperoleh hasilnya sebagai berikut

$$
\begin{aligned}
z & =\frac{314-309,33}{16,48} \\
& =0,72 .
\end{aligned}
$$

Maka nilai probabilitas dari proses produksi minyak kelapa adalah

$$
\begin{aligned}
P(Z \leq z) & =P(Z \leq 0,72) \\
& =0,7692 .
\end{aligned}
$$

Jadi probalitas penyelesaian produksi minyak kelapa diharapkan selesai dalam waktu 309,33 jam adalah 0,7692 . 


\section{PENUTUP}

Berdasarkan hasil analisis diperoleh waktu optimal yang diharapkan pada produksi minyak kelapa di CV. Usaha Bersama Kabupaten Sambas selesai dalam waktu 309 jam sebanyak 7.420kg. Probabilitas yang didapatkan dari menganalisis pengoptimalan waktu produksi minyak kelapa dengan metode PERT pada CV. Usaha Bersama Kabupaten Sambas sebesar 0,7692. Pertimbangan kendalakendala yang mengakibatkan keterlambatan dalam produksi minyak kelapa. Mengakibatkan metode PERT dapat digunakan untuk menentukan penjadwalan produksi minyak kelapa di CV. Usaha Bersama Kabupaten Sambas secara optimal.

\section{DAFTAR PUSTAKA}

[1] Siswanto. Operations Research, Jilid 2. Jakarta: Penerbit Erlangga; 2007.

[2] Herjanto E. Sains Manajemen.[Internet]. 2009 [update 2019 Juli 4; cited 2019 Juli 11]. Available from:

http://books.google.co.id/books?id=YeUjPfUMJbgC\&pg=PA123\&dq=pengertian+cpm+dan+pert \&hl=id\&sa=X\&ved=0ahUKEwiui-rs7ajjAHVRcCsKHU1ACdgQ6AEINTAD\#v=onepage\&q= pengertian $\% 20 \mathrm{cpm} \% 20$ dan $\% 20$ pert $\& \mathrm{f}=$ false

[3] Sofyan DK. Perencanaan dan Pengendalian Produksi. Yogyakarta; Graha Ilmu. 2013.

[4] Taha HA. Riset Operasi, Jilid 2. Jakarta: Binarupa Aksara; 1997.

[5] Siang JJ. (2011). Riset Operasi dalam Pendekatan Algoritmis. Yogyakarta: Andi Offset

[6] Wijaya A. Pengantar Riset Operasi. Jakarta: Mitra Wacana Media; 2011.

[7] Dipoprasetyo I. Analisis Network Planning Dengan Critical PATH Method (CPM) Dalam Usaha Efisiensi Waktu Produksi Pakaian Batik Pada Butik "Omahkoe Batik" Di Samarinda. Journal Administrasi Bisnis. 2016;4(4):1002-1015.

WALIYANTI : Universitas Tanjungpura, Jl. Prof. Dr. H. Hadari Nawawi waliyanti11@gmail.com

HELMI : Universitas Tanjungpura, Jl. Prof. Dr. H. Hadari Nawawi helmi132205@yahoo.ac.id

YUNDARI : Universitas Tanjungpura, Jl. Prof. Dr. H. Hadari Nawawi yundari@math.untan.ac.id 